\title{
Nota Final
}

\section{Adilson Citelli}

\section{SciELO Books / SciELO Livros / SciELO Libros}

CITELLI, A. Nota Final. In: CITELLI, A., ed.Comunicação e educação: dinâmicas midiáticas e cenários escolares [online]. Ilhéus, BA: EDITUS, 2021, pp. 207-212. Comunicação e educação series, vol. 7. ISBN: 978-65-8621-337-9. https://doi.org/10.7476/9786586213379.0015.

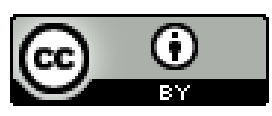

All the contents of this work, except where otherwise noted, is licensed under a Creative Commons Attribution 4.0 International license.

Todo o conteúdo deste trabalho, exceto quando houver ressalva, é publicado sob a licença Creative Commons Atribição 4.0.

Todo el contenido de esta obra, excepto donde se indique lo contrario, está bajo licencia de la licencia Creative Commons Reconocimento 4.0. 
NOTA FINAL

Adilson Citelli 

Este livro surge sob as circunstâncias particulares que marcam a vida brasileira e o resto do mundo em decorrência da pandemia do coronavírus. Conquanto a primeira redação do material tivesse ocorrido na passagem entre os últimos meses de 2019 e os primeiros de 2020 , ajustes e revisões posteriores alcançaram a terrível noite de insônia na qual ainda estamos mergulhados. Distanciamento social, confinamento, interdição das intimidades, testagens, vacinas, luto, vida remota, controle digital, lives, imunização, infectologista, virologia, falta de ar; a retórica da asfixia, infelizmente, apenas esclarece a dimensão do escombro. Ou, nos termos da filósofa italiana Donatella di Cesare

A catástrofe é ingovernável e traz à tona todos os limites da governança neoliberal. É uma interrupção que marca o curso da história, arranha a existência, muda o habitat, os hábitos, a habitação e a coabitação. Possui o tom irreversível e o carimbo do irreparável. Nada mais será como antes. $\mathrm{O}$ mundo de ontem parece ser o de um passado distante, desaparecido, colapsado. No presente, não poético e lutuoso, a respiração foi abalada (2020, p. 122. Itálico da autora).

De toda sorte, o fundamental, concernente aos dados apresentados e discutidos ao longo dos textos aqui reunidos, aponta um quadro complexo da vida escolar e que deve ser retomado em período pós-pandemia a fim de se promoverem as mudanças e avanços que todos desejamos. Em primeira visagem, depreende-se da nossa pesquisa a fragilidade que marca a infraestrutura das unidades educativas formais para enfrentar os reptos interpostos pela sociedade em crescente ritmo de digitalização, ademais evidenciados com o avanço da Sars-Cov2, o vírus que não é apenas "vingança da natureza, mas o resultado de uma cultura monotecnológica em que a tecnologia em si mesma perde suas origens e passa a querer dar origem a todo o resto" (HUI, 2020, p. 210). Ao mesmo tempo em que se requisitaram as diversas modalidades do ensino não presencial, a exemplo da educação a distância, do ensino remoto e das formas híbridas, a realidade das escolas, agravada pela leniência de boa parte das autoridades públicas, cujo olhar sobre o estado de emergência continuou mirando o berço esplêndido no qual dormita a pátria amada, mostrava a contraface de um sistema - em particular o público e de boa parte da rede privada - a funcionar nos limites das suas possibilidades, mesmo nos formatos in praesentia. ${ }^{1}$

1 Pesquisa feita em 2020 pelo Instituto de Arquitetos do Brasil - Departamento de São 
Nesta nota final não se trata de avançar em procedimentos analíticos que extrapolem as referências empíricas recolhidas em nossa pesquisa, repetimos, efetivada em momento anterior à pandemia. Entretanto, respeitados os desdobramentos que venhamos a ter do atual quadro sanitário, os dados recolhidos e as reflexões sobre eles permanecem trazendo contribuições importantes (como mostram alguns dos artigos componentes deste livro) para o melhor entendimento das dinâmicas comunicativo-educativas que atravessam a educação escolar, assim como dos possíveis projetos político-pedagógicos a serem construídos dias adiante, na esperança de que bafejados pelo fim da pandemia.

O foco que orientou o nosso trabalho esteve voltado ao entendimento acerca dos vínculos comunicação/educação (educomunicação): presença dos media e suas linguagens nas salas de aula; hábitos midiáticos de docentes e discentes; percepções do fluxo temporal frente aos discursos escolares e dos meios de comunicação; utilização dos dispositivos técnicos seja no andamento didático-pedagógico seja na vida cotidiana dos/das professores/as e alunos/as. Além dessas, inúmeras outras temáticas convergiram à preocupação central que orientou a citada investigação, tendo sido esclarecidas noutro passo deste livro.

Para o maior aprofundamento dos dados coletados, o material ganhou organização sob forma de artigos (e suas interconexões) elaborados por autores/autoras membros do MECOM, grupo de pesquisa sob a minha coordenação. Esta modalidade expositiva, devidamente tratada na Apresentação do volume, foi adotada por entendermos que é fundamental estreitar os vínculos (inter) formativos dos/das pesquisadores/as, haja vista a possibilidade aberta para se transitar por experiências diversas, facultar mútuas fertilizações, permitir a ampliação dos diálogos e as colaborações capazes de abranger os desafios imanentes à investigação científica. Desta sorte, buscou-se garantir a perspectiva de totalidade e integração ao longo do processo de pesquisa, análise e exposição do material coletado.

Paulo, em parceria com o Sindicato dos Professores de Ensino Oficial do Estado de São Paulo (APEOESP) e o Departamento Intersindical de Estatística e Estudos Socioeconômicos (DIEESE) mostra como os aproximados 3,8 milhões de estudantes, 200 mil professores e 40 mil funcionários transitam pelas quase 5,2 mil unidades de ensino básico público no estado mais rico do país: $82 \%$ das unidades não têm mais de dois sanitários para uso discente, $48 \%$ não possuem sanitário acessível para pessoas com deficiência, em 13\% inexiste quadra ou ginásio; $11 \%$ não registram pátios para atividades ao ar livre. Disponível em: https://www.iabsp.org.br/manual-tecnico-para-escolas-saudaveis/. Acesso: 10 jan. 2021. 
E para recuperar e sistematizar algumas das principais constatações presentes nos artigos, arrolamos os tópicos seguintes:

No Brasil há escolas de nível básico, mesmo quando se trata apenas da rede pública, marcadas por fundas dissimetrias. Existem unidades mais bem equipadas, estando outras em estágio de carência: faltam computadores, conexão à internet, os espaços estão deteriorados, existem óbices de acessibilidade, para nos limitarmos a alguns itens. Do mesmo modo, fatores econômicos e culturais esclarecem diferenças acentuadas entre docentes e, guardadas as particularidades, entre discentes. No primeiro grupo há variações atinentes à formação inicial e permanente, seja pelo percurso em graduações nem sempre envolvidas com o ensino de qualidade seja pelo descaso das políticas públicas em responder às necessidades objetivas do quadro docente, marcado por salários aviltados, desgaste profissional, falta de apoio para levar adiante as instigações solicitadas pelo mister didático-pedagógico. Os/as educadores/as cumprem exaustiva jornada em sala de aula (afora as atribuições burocráticas e funcionais), que para mais de $60 \%$ dos/das participantes da nossa pesquisa, é superior às 30 horas semanais; além de boa parte deles e delas completar a carga horária em mais de uma unidade de ensino, incluindo, em vários casos, o trânsito por cidades diferentes.

Os/as discentes, por sua vez, também vivem, em situações diversas, consequência de condições de existência desiguais. Registram-se origens sociais variadas, experiências culturais múltiplas, estratos econômicos distintos. Tal desconformidade é encontrada, igualmente, quando observadas as diferentes regiões do país, sendo as unidades públicas afeitas aos territórios mais ricos (estados e municípios) aquinhoadas com melhor infraestrutura e superior desempenho médio dos alunos e alunas. Aqui não cabe examinar os motivadores de projetos educativos bem sucedidos, conquanto em unidades carentes da federação, de que serve como uma espécie de referência permanente a cidade de Sobral, no Ceará. E, tão somente para reforçar o ponto concernente às assimetrias, basta acompanhar os resultados da pesquisa IBGE (Pnad Covid-19) feita entre os dias 16 e 22 de agosto de 2020, portanto, num dos momentos agudos da pandemia do Sars-Cov-2, e voltada a mostrar o número de estudantes que estavam sem qualquer atividade didático-pedagógica naquele período: Norte $(35,7 \%)$, Nordeste $(22,1 \%)$, Centro-Oeste $(10,7 \%)$, Sudeste $(10,1 \%)$ e Sul $(6,5 \%)$.

De toda sorte, o alunado revela a presença de jovens hábeis em operarem os media digitais, malgrado nem sempre com acesso integral à internet ou aparelhos móveis como os smartphones. As pressões contemporâneas, a 
pedirem respostas no aqui e agora - ritmo que parece ditado pelo estar permanentemente online - tanto podem comprometer a qualidade das aulas e os andamentos do aprendizado quanto acabam expondo discentes e docentes a múltiplos problemas no plano psicológico, de que servem os exemplos da síndrome de Burnout - a doença do trabalho em plena expansão junto ao magistério -, as ansiedades e depressões, a hiperatividade.

A entrada das tecnologias na escola é uma realidade demonstrada pela pesquisa. Entenda-se: mesmo que a unidade educativa não possua determinados equipamentos para fins didáticos, a presença do celular, dos computadores, da internet é algo objetivo no cotidiano da maioria dos professores e professoras, alunos e alunas. Isto requisita da cultura, digamos, tradicional da escola, uma nova forma de relacionamento com as técnicas e estratégias para incorporá-las aos andamentos didático-pedagógicos. Tal assertiva, extraída dos dados coletados, remete a outra reflexão: não cabe pensar as tecnologias de modo instrumental e sim como mediadoras da aprendizagem. Vistos sob tal ângulo, os recursos, ao menos alguns dos mais referidos (internet, computadores, celulares, tablets), precisam fazer parte do ecossistema comunicativo das escolas, e de algum modo - como vem acontecendo em vários casos, segundo depoimentos de docentes e discentes - colaborar no ajuste de passo entre a sala de aula e o mundo inclusivo, no qual os desafios dos dispositivos e suas linguagens estão fortemente presentes.

Observe-se, contudo, que existe muito a se fazer nos ambientes da educação escolar quanto ao debate envolvendo a circulação das tecnologias, dos media e suas linguagens. Do ponto de vista docente, existe plena consciência desta nova circunstância no interior da qual o ensino formal está ocorrendo, e que, de algum modo, cabe aos professores e professoras o papel importante de orientação no uso de tais meios. Ou, nos nossos termos, de implementar uma proposta educomunicativa capaz de contemplar os desafios requisitados pela educação midiática.

A pesquisa realizada reflete, de vários modos, a complexidade da vida em curso e de como ela se manifesta no ensino formal, no cotidiano de discentes e docentes. As diversificadas plataformas digitais difundem informações em largos segmentos daqueles dois grupos, elaborando outras circunstâncias culturais, ampla gama de interesses que incluem os jogos, a música, as notícias, e um repertório múltiplo de linguagens, signos e símbolos. Esta constatação está materializada nas figuras e gráficos da pesquisa, nos quais é possível reconhecer como ocorre a busca de entretenimento, conhecimentos, formas de interação, trocas mensageiras etc. O grande desafio, 
presente nas muitas falas de professores/as e alunos/as, é como fazer circular todo este material (e as suas implicações sociais e culturais) no ambiente escolar - ainda amparado em concepções propedêuticas e limitações regimentais referentes ao controle do tempo (em seus poucos congruentes ritmos que marcam ou as aulas formais ou os ditames midiáticos e digitais), aos mecanismos de distribuição dos conteúdos curriculares e às estratégias de exposição das disciplinas.

É preciso considerar o fato de existirem propostas visando a desenvolver as competências essenciais, segundo formuladas na Base Nacional Comum Curricular (BNCC), e alinhando-se entre elas o entendimento das dinâmicas tecnológicas, dos sentidos da cultura informacional, das operações sobre as linguagens midiáticas. Trata-se de um novo processo de aprendizagem (ou de participação cidadã, se quisermos ampliar a ideia) que não se faz desconhecendo os mediadores comunicacionais. Efetivamente, as mudanças nos hábitos de consumo das tecnologias pedem reorientações das práticas em sala de aula. No lugar das dominantes exposições verbais ou do uso do quadro negro como quase único apoio para apresentação da matéria, outras estratégias didático-pedagógicas vêm sendo propostas (malgrado não excluídas as duas acima citadas), a exemplo da aprendizagem por projetos, das metodologias ativas, da sala de aula invertida - a flipped classroom tem o propósito de levar alunos e alunas a mobilizarem, em suas casas, os recursos presenciais e virtuais com vistas à preparação de tópicos programáticos, realização de pesquisas, etc. Para tanto, pode-se acionar as tecnologias da informação e da comunicação, nos formatos de videoaulas, jogos de computador, investigações de várias naturezas permitidas pela internet.

$\mathrm{Na}$ presente quadra histórica, a preferência é crescente pelas informações digitais velozes, encontradas nas multiplataformas, geralmente agregadas às possibilidades hipertextuais. Vídeos curtos, memes, GIFs e outras expressões narrativas da rede digital, compostas por mensagens diretas e instantâneas já vêm sendo utilizadas entre os/as estudantes, como ficou demonstrado em inúmeras das análises componentes deste livro. Tal fato, cujas práticas e consequências devem ser mais bem avaliadas pela escola, pois possuem implicações em vários níveis formativos do alunado, esclarece, contudo, uma certa emergência do presente, algo não muito afinado com a tradição discursiva escolar, calcada, por exemplo, no texto longo, com regras argumentativas, sequências de exposição, para ficarmos em poucos aspectos.

Dos textos lidos, é possível depreender a existência de formas de ser e existir circundadas por uma realidade atravessada por dispositivos móveis, 
reconfigurações cronotópicas, imaterialidades, que terminam pressionando pela adoção de novas estratégias de ensino-aprendizagem. De certo modo, solicitam a revisão ou redefinição do lugar e do papel representado pela escola. Enfim, algumas das várias circunstâncias que recortam a complexidade do tempo em curso e refletidas no ambiente das salas de aula podem ser reconhecidas ao longo da nossa pesquisa. E esperamos que os dados e reflexões aqui ensejados tragam contributos visando a repensar a educação básica formal, tendo em vista os desafios e possibilidades oferecidos pelos processos comunicacionais.

\section{Referências}

DI CESARE, D. Vírus Soberano? Belo Horizonte/Veneza: Âyiné, 2020.

HUI, Y. Tecnodiversidade. São Paulo: UBU, 2020. 